\title{
DESENVOLVIMENTO DE PROCESSOS PSÍQUICOS SUPERIORES NA APRENDIZAGEM DE LÍNGUA INGLESA: ANÁLISE DE PRODUÇÕES ESCRITAS DE ESTUDANTES DO PROGRAMA PARANÁ FALA INGLÊS DA UNESPAR
}

\author{
The development of superior psychic processes in English language \\ learning: an analysis of students 'written productions at Unespar's Paraná \\ Speaks English Program
}

\author{
Alisson Davis de Souza e SILVA \\ Universidade Estadual do Paraná \\ alisson.silva.27@estudante.unespar.edu.br \\ https://orcid.org/0000-0002-3290-4130 \\ Alessandra Augusta Pereira da SILVA \\ Universidade Estadual do Paraná \\ alessandra.silva@unespar.edu.br \\ http://orcid.org/0000-0002-0189-2173
}

RESUMO: Nesta pesquisa investigamos o processo de aprendizagem da escrita em língua inglesa referente à potencialidade de desenvolvimento dos processos psíquicos superiores (PPS) a partir de produções textuais de participantes do Programa Paraná Fala Inglês da Unespar. Em outras palavras, refletimos acerca da formação linguístico-discursiva em uma política de capacitação linguística voltada para a internacionalização. $\mathrm{O}$ processo teórico-metodológico tomou por base $\mathrm{o}$ Interacionismo Sociodiscursivo para as questões relacionadas à análise linguístico-discursiva (BRONCKART, 2007; MACHADO; BRONCKART, 2009; BRONCKART, 2008; CRISTOVÃO, 2008), bem como a Psicologia Histórico-cultural, cuja linha subsidiou a discussão e análise acerca dos potenciais de desenvolvimento dos PPS (VIGOTSKI, 2009; MARTINS, 2013; SILVA, 2015). Os resultados da investigação indicam: a) identificação de possibilidades de aprendizagem da escrita em língua inglesa contemplados no planejamento curricular; b) melhoras gradativas na organização pedagógica do planejamento; c) oportunidade de letramento digital aos estudantes; d) levantamento dos Focos de Atenção que estão voltados para a produção escrita em uma sequência argumentativa e temática viagens; e) identificação de potenciais de desenvolvimento dos PPS nas produções textuais de forma articulada entre si; e f) expansão da capacidade da argumentatividade e exposição

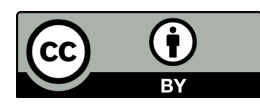


de posicionamento articulado com potencial desenvolvimento da abstração e generalização de conceitos articulados, sobretudo a atenção. PALAVRAS-CHAVE: Aprendizagem e Desenvolvimento; Língua Inglesa; Paraná Fala Inglês.

ABSTRACT: In this research we investigate the learning process of writing in the English language regarding the potential development of higher psychic processes (HPP) from the textual productions of participants in Unespar Paraná Speaks English Program. In other words, we ponder over the linguistic-discursive formation in a language qualification policy directed towards internationalization. The theoretical-methodological process was based on Sociodiscursive Interactionism for questions related to linguistic analysis (BRONCKART, 2007; MACHADO; BRONCKART, 2009; BRONCKART, 2008; CRISTOVÃO, 2008), as well as Cultural-Historical Psychology, which fostered the discussion and analysis of the higher psychic processes' developmental potentials (VIGOTSKI, 2009; MARTINS, 2013; SILVA, 2015). The results indicate: a) identification of possibilities for learning English language writing contemplated in the curricular plans; b) gradual improvements in the pedagogical organization of planning; c) opportunity for student digital literacy; d) survey of the focuses of attention that are directed at written production, argumentative sequence, and traveling as a theme; e) identification of developmental potentials of HPP in textual productions in an articulated way; f) expansion of argumentative capacity and exposure of articulated positioning with potential development of abstraction and generalization of articulated concepts, especially attention. KEYWORDS: Learning and Development; English Language; Paraná Speaks English.

\section{INTRODUÇÃO}

Embora a discussão acerca da internacionalização no Brasil venha com o próprio processo de globalização, destacamos como precursores desse tipo de ação de internacionalização no Brasil para o Ensino Superior, a nível nacional, o Programa Ciências sem Fronteiras e, como política de capacitação linguística, o Inglês/Idiomas sem Fronteiras, criados pelo Governo Federal e que tinham como objetivo impulsionar diálogos educacionais com outros países (MARSON, 2017; SILVA; SILVA, 2018, 2021).

Nas Universidades Estaduais do Paraná, com a necessidade de políticas de internacionalização, especificamente de capacitação linguística, criou-se, formalmente 
em 2014, o PFI, sob a coordenação das sete universidades estaduais paranaenses ${ }^{1}$ com $^{2}$ financiamento advindo da Unidade Gestora do Paraná (UGF) por meio da Secretaria de Ciência, Tecnologia e Ensino Superior do Paraná (SETI)², objetivando capacitar linguisticamente a comunidade universitária em idiomas estrangeiros para participar de oportunidades relacionadas à internacionalização, como, por exemplo, a mobilidade acadêmica, publicação de artigos, participação em eventos internacionais etc.

Sendo um Programa organizado por fases/etapas, sua delimitação temporal da primeira fase, para o inglês, deu-se entre 2014 e 2016, segunda, entre 2017 e 2019 e, terceira, em andamento, entre 2019 e 2021 . A partir do PFI, outras políticas de capacitação correlacionadas foram criadas no estado do Paraná, como o Paraná Fala Francês (implantado), Paraná Fala Japonês (a ser implantado), Paraná Fala Espanhol (ainda não implantado) $)^{3}$, o Programa de Mobilidade Internacional do Paraná Fala Idiomas, ações conjuntas relacionados ao English as Medium of Instruction (EMI), dentre outros, e, na Universidade Estadual do Paraná, doravante Unespar, também o Programa de Línguas Estrangeiras da Unespar (PROLEN).

Nesse meio tempo, pesquisadores e pesquisadoras debruçaram-se sobre essa nova política de internacionalização. Uma delas é Marson (2017) que, ao propor compreender o PFI a partir da percepção dos participantes ativos do programa no contexto da UEL, afirmou que a política pôde contribuir para a internacionalização do Ensino Superior e também mostrou ser necessário o replanejamento nos âmbitos institucional e pedagógico, bem como a necessidade de ampliação de oferta no atendimento das demandas institucionais específicas.

No contexto da Unespar, Silva e Silva $(2018,2021)$ apontam que o PFI foi implementado em um momento de mudanças estruturais na instituição, assim, sua identidade se encontra em processo inicial, caminhando para uma consolidação. Também indicaram ser necessário investimento em políticas linguísticas de base para que a universidade aumente seu percentual de pessoas da instituição que almejam participar de

\footnotetext{
${ }^{1}$ Universidade Estadual de Londrina (UEL), Universidade Estadual de Maringá (UEM), Universidade Estadual de Ponta Grossa (UEPG), Universidade Estadual do Centro-Oeste do Paraná (Unicentro), Universidade Estadual do Norte do Paraná (UENP), Universidade Estadual do Oeste do Paraná (Unioeste) e Universidade Estadual do Paraná (Unespar).

2 Atualmente, a Secretaria tornou-se uma Superintendência do Gabinete do Governador Ratinho Junior.

${ }^{3}$ Como o Paraná Fala Espanhol não foi implementado no Estado do Paraná, a Unespar tomou a iniciativa de implementar um programa da instituição, intitulado Unespar Fala Espanhol (UNESPAR, 2020).
} 
ações de internacionalização (motivação para a construção do PROLEN e de um Centro de Línguas da universidade, por exemplo).

Apesar dessas pesquisas, em um contexto de Internacionalização do Ensino Superior no Paraná, nota-se que há poucos trabalhos que versam sobre o Programa Paraná Fala Idiomas/Línguas Estrangeiras, especificamente o $\mathrm{PFI}^{4}$, com foco na aprendizagem e desenvolvimento, ainda mais sob a perspectiva vigotskiana.

É nesse contexto do Programa na Unespar, sob as lentes do Interacionismo Sociodiscursivo (ISD) e da Psicologia Histórico-Cultural (PHC), que objetivamos investigar o processo de aprendizagem da escrita em língua inglesa (LI) e potenciais de desenvolvimento dos processos psíquicos superiores (PPS) a partir da delimitação de produções textuais (PT) de estudantes ${ }^{5}$ do Programa na instituição. Em outras palavras, ensejamos refletir acerca da formação linguístico-discursiva desses estudantes a partir de uma política de capacitação linguística voltada para a internacionalização. Dessa forma, buscamos responder às seguintes perguntas: Qual o contexto em que o processo de aprendizagem se insere (delimitado no contexto de ensino) a partir do material de planejamento dos professores do Programa? Quais Focos de Atenção estão presentes no comando ${ }^{6}$ de produção escrita? Quais PPS foram potencializados no processo de escrita dos estudantes?

Conforme exposto, identificamos que não há nenhuma pesquisa que enfoque a aprendizagem e desenvolvimento por meio da escrita em LI de adultos articulada ao PFI. Assim, esta pesquisa insere-se na literatura como inédita, pois ao analisar em que aspectos o PFI tem contribuído para a formação linguístico-discursiva de seus estudantes

\footnotetext{
${ }^{4}$ Elencamos algumas pesquisas que vertem sobre o PFI e/ou internacionalização de modo amplo publicadas em periódicos, anais de eventos científicos, dissertações e teses: Marson e Borges (2015), El Kadri e Di Raimo (2017), El Kadri, Gimenez e El Kadri (2019), Marson (2017), Marson e Furtoso (2015), Petreche e Senefonte (2017), Pinheiro, Baretta e Souza (2017), Quadros-Zamboni (2018), Rodrigues, Becher e Busser (2018), Sanches (2019), Santos e Tulio (2018), Senefonte (2019) e Silva e Silva (2018, 2019, 2021). Algumas dessas pesquisas compõem a coletânea de pesquisas sobre o PFI organizada por Rios-Registro, Novelli e Calvo (2021). Atualmente, diversas pesquisas estão sendo iniciadas ou em andamento no que se refere a essa e outras políticas de capacitação linguística sobre/na Unespar e outras instituições.

${ }^{5}$ Cabe ressaltar que o termo estudantes, nesse contexto, refere-se aos estudantes do PFI, isto é, qualquer um que mantinha vínculo com a instituição, sendo a maioria estudantes de graduação. Também participam estudantes de pós-graduação, docentes, agentes universitários/as, bolsistas de programas etc.

${ }^{6}$ Em relação à escolha do termo comando para nos referirmos à atividade de escrita em questão, corroboramos com Silva (2015, p. 25) que, considerando o trabalho de autores que discutem a questão, pontua comando e instruções como constituintes de uma consigna, ou seja, um conjunto de tarefas e/ou orientações direcionadas ao estudante.
}

Revista X, v. 16, n. 3, p. 822-846, 2021. 
em termos de potenciais de desenvolvimento dos PPS, ela define-se pela discussão da relação entre o processo de aprendizagem da produção escrita e o ensino de LI para adultos em um contexto específico.

Além disso, a singularidade da pesquisa na tríade adultos aprendizes/LI/ produção escrita revela o aspecto inovador da pesquisa ao fazê-la na perspectiva da PHC. Assim, justifica-se o fato de discutir uma das políticas implantadas no nível de suas possíveis contribuições para a aprendizagem de uma língua estrangeira, delimitada na aprendizagem da escrita.

Dessa forma, na sequência, apresentamos as bases teóricas desta investigação, contemplando o ISD e o conceito de aprendizagem e desenvolvimento na PHC, seguida da metodologia e resultados de análise.

\section{Interacionismo Sociodiscursivo e Vigostki: relação entre aprendizagem e desenvol- vimento}

As questões teóricas basilares que subjazem nossa investigação são fundamentadas no ISD e na PHC e o recorte para este artigo está ancorado nos princípios gerais do ISD e no conceito de aprendizagem e desenvolvimento da PHC.

O ISD (BRONCKART, 2007; MACHADO; BRONCKART, 2009; BRONCKART, 2008; CRISTOVÃO, 2008) incorporou em sua base teórico-epistemológica estudos do grupo de Vigotski (Teoria/Psicologia Histórico-Cultural). Assim, considera o ser humano como ser social em constante desenvolvimento em suas mais diversas atividades, incluindo a linguagem, que é central para o ISD.

A linguagem, para o ISD, se caracteriza como um artefato simbólico que determina, junto a outros aspectos, as condutas humanas que dão origem à socialização e à história. Nesse sentido, a linguagem tem papel muito pertinente no desenvolvimento psíquico humano, sobretudo no desenvolver consciente sobre si e o mundo para o agir social (CRISTOVÃO, 2008, p. 4).

No arcabouço de pesquisas desenvolvidas no ISD, a linguagem toma também um protagonismo, sobretudo na análise de textos verbais. Assim, inseridos no campo da Linguística Aplicada, o ISD propõe uma análise textual que se divide em níveis (a) organizacional, (b) enunciativo e (c) semântico (BRONCKART, 2008). Em (a), tem-se o levantamento da organização temática; em (b), o estudo das modalizações, vozes, índice de pessoas e protagonistas. Por fim, o nível (c) envolve os elementos do agir, além do cruzamento das análises anteriores (CRISTOVÃO; MOTT-FERNANDEZ, 2014, p. 134). 
Na perspectiva de análise bronckartiana, entende-se que,

para a realização de qualquer análise no campo das ciências humanas, devemos desenvolver uma análise descendente a qual, em primeiro lugar, visa definir o contexto sócio-histórico mais amplo e a situação de produção do texto, os quais influenciam diretamente os sentidos produzidos no e pelo texto. $\mathrm{O}$ enfoque dado a esse aspecto das análises refere-se a: o que considerar, ou como abordar o texto ao realizar o levantamento dos temas mobilizados pelo agente-produtor no desenvolvimento de sua ação de linguagem? (CRISTOVÃO; MOTTFERNANDEZ, 2014, p. 132-3).

Inserida nessa análise descendente, no nível organizacional, Bronckart (2007, p. 97) afirma que o conteúdo temático consiste no "conjunto das informações que nele (no texto) são explicitamente apresentadas", isto é, o que de linguisticamente foi materializado por alguém (voz). Neste trabalho, os procedimentos de análise recaíramse, principalmente, nesse nível de análise, delimitados na análise de orientação temática (SOT), e identificação e tratamento do conteúdo temático (STT). Para tanto, analisase o texto a partir de seus sintagmas nominais (nomes) e verbais (ações), bem como modalizadores e afins. Conforme o autor, o SOT é caracterizado por "segmentos de introdução, de apresentação ou de lançamento de um tema" (BRONCKART, 2008, p. 163), enquanto que o STT se constitui como segmentos "produzidos pelo [sujeito autor do texto], em resposta a uma questão ou dando prosseguimento a um lance temático" (ibidem), ou seja, o desdobramento de um SOT.

Conforme Lanferdini (2012, p. 45-46), as “análises do nível enunciativo são voltadas à verificação dos mecanismos de responsabilização enunciativa, englobando as marcas de pessoa, marcas de inserção de vozes, ocorrência ou não de modalização, modalizadores subjetivos e adjetivos". Para esta pesquisa, utilizamos recorte de questões de modalização ao analisarmos a argumentatividade.

No que concerne à $\mathrm{PHC}$, destacamos alguns conceitos que embasaram nossa investigação relacionados ao objetivo da pesquisa, a saber, relação dos conceitos científicos e espontâneos com a aprendizagem de língua estrangeira, desenvolvimento dos PPS e, por fim, a partir desses conceitos, a categoria de análise foco de atenção (SILVA, 2015). Conceitos que serão tratados daqui por diante.

Ao tratar da aprendizagem de línguas estrangeiras, Vigostki (2009) explicita que elas se dão inversamente à aprendizagem da primeira língua do falante, pois a aprendizagem perpassa obrigatoriamente pelos conceitos científicos, ou seja, o aprendiz precisa passar por estágios diferentes no processo de sua aprendizagem, considerando, 
o processo de ciência (tomar consciência) do objeto a ser apreendido, em um ambiente formal de aprendizagem, num processo sistematizado de apropriação, e que necessitam dele, portanto, das capacidades de abstração, análise, síntese e generalização, em um processo dialético, diferentemente dos conceitos espontâneos que podem ser apreendidos no cotidiano das pessoas, em suas atividades empíricas e de forma intuitiva.

Em outras palavras, os conceitos científicos compreendem o conhecimento de conceitos que necessariamente precisam de outros conceitos (mais primários) para serem apropriados, são generalizações mais complexas e, portanto, mais amplas do conhecimento. Retomando Vigostki (2009), é a generalização da generalização. No conceito espontâneo, pode haver uma relação direta entre o aprendiz e o objeto material conceituado, envolvendo, portanto, relações mais diretas e empíricas no processo de sua apropriação.

Para Vigostki (2009, p. 338), “A questão da aprendizagem e do desenvolvimento é o centro da análise da origem e da formação dos conceitos científicos". Em relação à aprendizagem de uma língua estrangeira, o autor (2009) destaca que

o domínio de uma língua estrangeira eleva a língua materna da criança ao nível superior quanto à tomada de consciência das formas linguísticas, da generalização dos fenômenos da linguagem, de um uso mais consciente e mais arbitrário da palavra como instrumento de pensamento e expressão de conceito (VIGOTSKI, 2009, p. 267, grifos nossos).

Esse processo de aprendizagem, ao considerar a necessária tomada de consciência das formas linguísticas, não acontece de forma natural, intuitiva. Nesse caso, ela se dá num contexto sistematizado, ou seja, na escola. Ao pensar nessa aprendizagem na idade adulta, Silva (2015) explicita que

na língua estrangeira essa questão é ainda mais complexa, pois, se há um grande salto qualitativo na apropriação da escrita da primeira língua (materna), somamos a isso o fato de que na apropriação da língua oral também há esse salto, já que estamos discutindo o ensino de uma língua estrangeira e, portanto, partimos, desde o início, com o ensino baseado em conceitos científicos, portanto, abstratos. Na aprendizagem da língua estrangeira o aluno precisa, desde o início, tomar consciência do que está aprendendo para, somente depois, se apropriar do conteúdo e tornar suas ações operações. Ou seja, nesse segundo momento ele não precisa mais pensar em cada parte de sua ação ao, por exemplo, escrever um texto autobiográfico (SILVA, 2015, p. 77). 
Em outras palavras, podemos afirmar que a aprendizagem de uma língua estrangeira na escola é um processo de apropriação de conceitos científicos ao serem trabalhados em espaços formais - espaço privilegiado para a aprendizagem; diferentemente da aquisição da língua materna, cujo processo de apropriação ocorre via conceitos espontâneos em contextos não escolares ${ }^{7}$.

Essa aprendizagem consciente pode potencializar o desenvolvimento, que começa a acontecer simultâneo ao processo de aprendizagem de modo dialético e histórico. Segundo Vigotski (2009), o desenvolvimento começa quando o indivíduo entra em contato com a palavra ${ }^{8}$ e se dá num processo complexo e delicado. Assim, consiste numa "progressiva tomada de consciência dos conceitos e operações do próprio pensamento" (VIGOTSKI, 2009, p. 279) em inter-relação.

Com essa discussão, nos questionamos: o que o desenvolvimento desenvolve? Para Vigotski, como seres sociais, além dos processos psíquicos inferiores $\left(\mathrm{PPI}^{9}\right)$ elementares, biológicos, instintivos - podemos desenvolver os PPS, por meio dos quais nos tornamos humanos, seres sociais.

Essas funções, ou como chamamos neste trabalho de processos, por considerar sua interrelação, são articuladas entre si e podem ser classificadas como: sensação, percepção, atenção, memória, linguagem, pensamento, imaginação, emoções e sentimentos e as operações lógicas de raciocínio, como a análise e síntese, a comparação, a generalização e a abstração (MARTINS, 2013). Em outras palavras, o desenvolvimento de um ser humano é a unidade dos PPI e PPS ou FPI e FPS. Conforme Silva (2015),

\begin{abstract}
Vigotski (2009) não faz diferenciação entre função e processo psíquico e insere, nesse grupo, a linguagem, o pensamento (por conceitos), a imaginação, os sentimentos, a imagem, a sensação, a percepção, a emoção, a atenção e a memória. Ainda, em um segundo momento, ao mencionar a formação de ações mentais, ele introduz os processos de análise e síntese e as ações analítico-sintéticas, como a abstração e a generalização (que somente são possíveis através da mediação pela linguagem), ou ainda mescla os primeiros processos com aqueles outrora apresentados, quando apresenta requerimentos para o desenvolvimento de conceitos (SILVA, 2015, p. 71).
\end{abstract}

\footnotetext{
${ }^{7}$ Podemos também ter aprendizagem de língua materna na escola bem como língua estrangeira fora da escola, mas não é nosso foco discutir essa questão.

${ }^{8}$ Para uma discussão acerca do conceito "palavra", ver Vigotski (2009), capítulo 7.

${ }^{9}$ Conforme Martins (2012, p. 62), as funções elementares "transcorrem em direta dependência da maturação cerebral, orgânica", ou seja, são marcadas pelo reflexo e imediatismo, de acordo com o estímulo do ambiente, enquanto que as superiores se complexificam das elementares e têm caráter social.
} 
Propostas de pesquisa que incidem no processo de aprendizagem e desenvolvimento da LI sob a perspectiva vigostikiana junto à Linguística Aplicada e ao ISD já foram realizadas para olhar o contexto de formação inicial de professores de Letras e a natureza do seu trabalho (SILVA, 2015), justamente porque a PHC, preconizada principalmente por Vigotski, toma como objetivo entender o desenvolvimento humano, ou seja, o desenvolvimento dos PPS.

Nessa mesma perspectiva, Silva (2015) desenvolveu em sua tese a categoria de análise Focos de Atenção (FA) a partir da necessidade de identificar direcionamentos de conteúdos específicos em instruções (comandos) de materiais didáticos como potenciais de desenvolvimento dos PPS. Assim, por meio da análise linguístico-discursiva, ela discutiu as instruções como mediações que orientavam o conteúdo didático, que, por sua vez, potencializaria (ou não) o desenvolvimento dos PPS. Reproduzimos, a seguir, o quadro produzido por Silva (2015) que consiste em sintetizar o que exploram as instruções em termos de PPS.

Quadro 1: PPS e Instruções.

\begin{tabular}{|c|c|}
\hline PSS & Instruções que exploram \\
\hline Sensação & Órgãos de sentidos \\
\hline Percepção & Órgãos de sentidos que auxiliam na formação de uma imagem, ideia, \\
pensamento
\end{tabular}

Fonte: (SILVA, 2015, p. 253).

Para a autora, o FA direciona o estudante para determinado aspecto da atividade no comando de produção, podendo o foco ser explícito ou implícito. O FA, assim, implica na delimitação de um conteúdo específico, por exemplo, um comando que pede exercício Revista X, v. 16, n. 3, p. 822-846, 2021. 
de tradução teria como foco de atenção, nessa perspectiva, a estrutura e o léxico, que poderia potencializar o desenvolvimento do PPS memória imediata. Atividades de completar lacunas ou nomenclaturas gramaticais também teriam como foco de atenção a estrutura linguística e, conforme análises de Silva (2015), poderiam potencializar o desenvolvimento da memória imediata e da atenção.

Ainda segundo a pesquisadora, a partir da análise de alguns comandos que constituíram seu corpus de pesquisa, "a mobilização de memória potencializada indicava somente uma memória curta para execução de exercícios mecânicos, sem uma articulação entre outros processos psíquicos superiores, necessários para o desenvolvimento humano" (SILVA, 2015, p. ix). Isso chama a atenção para a forma com a qual a atividade é pensada ao implicar em determinado conteúdo, que, por sua vez, pode potencializar o desenvolvimento de PPS.

No contexto de sala de aula, consideramos ainda a figura do professor como mediador $^{10}$ do processo de aprendizagem e desenvolvimento do sujeito-estudante, utilizando-se de instrumentos mediadores como, por exemplo, o material didático.

Nesta pesquisa, analisamos o comando de produção para discutir como se dá o relacionamento entre os FA identificados e a produção escrita dos estudantes no processo de aprendizagem da escrita de LI durante os cursos de inglês do PFI. Essa análise do foco atrelado à análise contextual pôde contribuir para amadurecermos investigações em busca de respostas para as perguntas desta pesquisa.

Após essa breve exposição de alguns conceitos basilares da nossa pesquisa, passamos a discutir, mais especificamente, os meios pelos quais a pesquisa se deu, ou seja, o processo metodológico.

\section{METODOLOGIA DE PESQUISA}

Este artigo é resultado de uma pesquisa vinculada a um regime de trabalho de dedicação exclusiva da Unespar em articulação com uma investigação do Programa de Iniciação Científica no biênio 2018/2019 da mesma instituição, ambas atreladas ao PFI, a partir de um estudo de caso, conforme características apontadas por Lüdke e André (1986, p. 18-20), portanto, de natureza qualitativa (interpretacionista), cujo maior objeto de análise é o ser humano, como um ser social e histórico, ou seja, um ser que interage, interpreta, constrói sentido e é um agente de reprodução e/ou transformação social.

\footnotetext{
${ }^{10}$ Apesar de central na teoria vigotskiana, o papel da mediação não é aqui aprofundado, portanto, ver Vigotski (2009), Martins (2012, 2013) e Silva (2015).
} 
Considerando que o objetivo geral incidiu em investigar o processo de aprendizagem da escrita em LI e potenciais de desenvolvimento dos PPS a partir da delimitação de PT de estudantes do PFI Unespar, a pesquisa compreendeu três etapas metodológicas, conforme quadro a seguir.

Quadro 2: Perguntas de pesquisa, dados e procedimentos de análise.

\begin{tabular}{|c|c|c|}
\hline Perguntas de Pesquisa & Dados & Procedimentos de análise \\
\hline $\begin{array}{c}\text { Qual o contexto em que o } \\
\text { processo de aprendizagem } \\
\text { se insere (delimitado no } \\
\text { contexto de ensino) a partir do } \\
\text { material de planejamento dos } \\
\text { professores do Programa? }\end{array}$ & $\begin{array}{c}\text { Literatura disponível } \\
\text { sobre o PFI } \\
\text { Material de } \\
\text { professores do PFI }\end{array}$ & $\begin{array}{c}\text { Análise do contexto } \\
\text { de produção a partir } \\
\text { do viés do ISD } \\
\text { Análise organizacional }\end{array}$ \\
$\begin{array}{c}\text { Quais Focos de Atenção } \\
\text { estão presentes no comando } \\
\text { de produção escrita? }\end{array}$ & $\begin{array}{c}\text { Comando de produção } \\
\text { escrita }\end{array}$ & $\begin{array}{c}\text { Análise organizacional } \\
\text { (orientação e tratamento } \\
\text { temático) }\end{array}$ \\
\hline $\begin{array}{c}\text { Quais PPS foram potencializados } \\
\text { no processo de escrita dos } \\
\text { estudantes? }\end{array}$ & $\begin{array}{c}\text { Produções escritas dos fos FA } \\
\text { estudantes do PFI }\end{array}$ & $\begin{array}{c}\text { Análise organizacional } \\
\text { (orientação e tratamento } \\
\text { temático) e enunciativa } \\
\text { (modalização) }\end{array}$ \\
\hline
\end{tabular}

Fonte: os autores.

Cada pergunta de pesquisa corresponde a um objetivo específico da investigação e, consequentemente, a uma etapa do processo metodológico.

Dessa forma, em um primeiro momento, para fazer o levantamento do contexto em que o processo de aprendizagem se insere, delimitado no contexto de ensino, a partir do material de planejamento dos professores do Programa, foram realizadas:

a. investigação da literatura disponível sobre as perspectivas teóricas e metodológicas que subsidiou a pesquisa: o ISD e a PHC;

b. síntese dos resultados de pesquisas sobre PFI em literatura disponível;

c. coleta e análise do material de planejamento dos professores do PFI a fim de delimitarmos o contexto de aprendizagem dos estudantes que, por se limitar ao planejamento docente, culminou no levantamento do contexto de ensino. 
Como nossa delimitação recaiu sobre produções escritas de estudantes que fizeram parte de três semestres consecutivos de cursos do Programa, selecionamos somente o planejamento referente à turma de nível pré-intermediário no semestre 2017/2, intermediário de 2018/1 e pós-intermediário de 2018/2, que tratavam da modalidade de produção escrita.

Esse estudo de contexto tomou como base os procedimentos de análise do ISD, o que nos levou à segunda etapa da pesquisa: coletar e analisar o comando, instrução que mediou a produção escrita dos estudantes do PFI.

O comando consistia em uma atividade específica elaborada pela SmrtEnglish e aplicado em dois momentos:

- $1^{\mathrm{o}}$ momento: processo seletivo não eliminatório (teste de nivelamento) dos estudantes em 2017/2 para cursarem Inglês Geral em nível pré-intermediário primeiro semestre.

- $\quad 2^{\circ}$ momento: atividade avaliativa escrita produzida no final de $2018 / 2$ - terceiro semestre.

Para compor dados de análise da última pergunta da pesquisa, o critério implicou na seleção de PT de estudantes que fizeram a atividade do comando de produção no início de 2017/2 e no fim de 2018/2. No entanto, tais PT deveriam pertencer a estudantes cuja participação tenha perpassado também o semestre 2018/1.

Ao coletarmos e organizarmos as produções textuais (PT) dos estudantes, sistematizamos os dados da seguinte forma: 
Gráfico 1: Sistematização das PT.

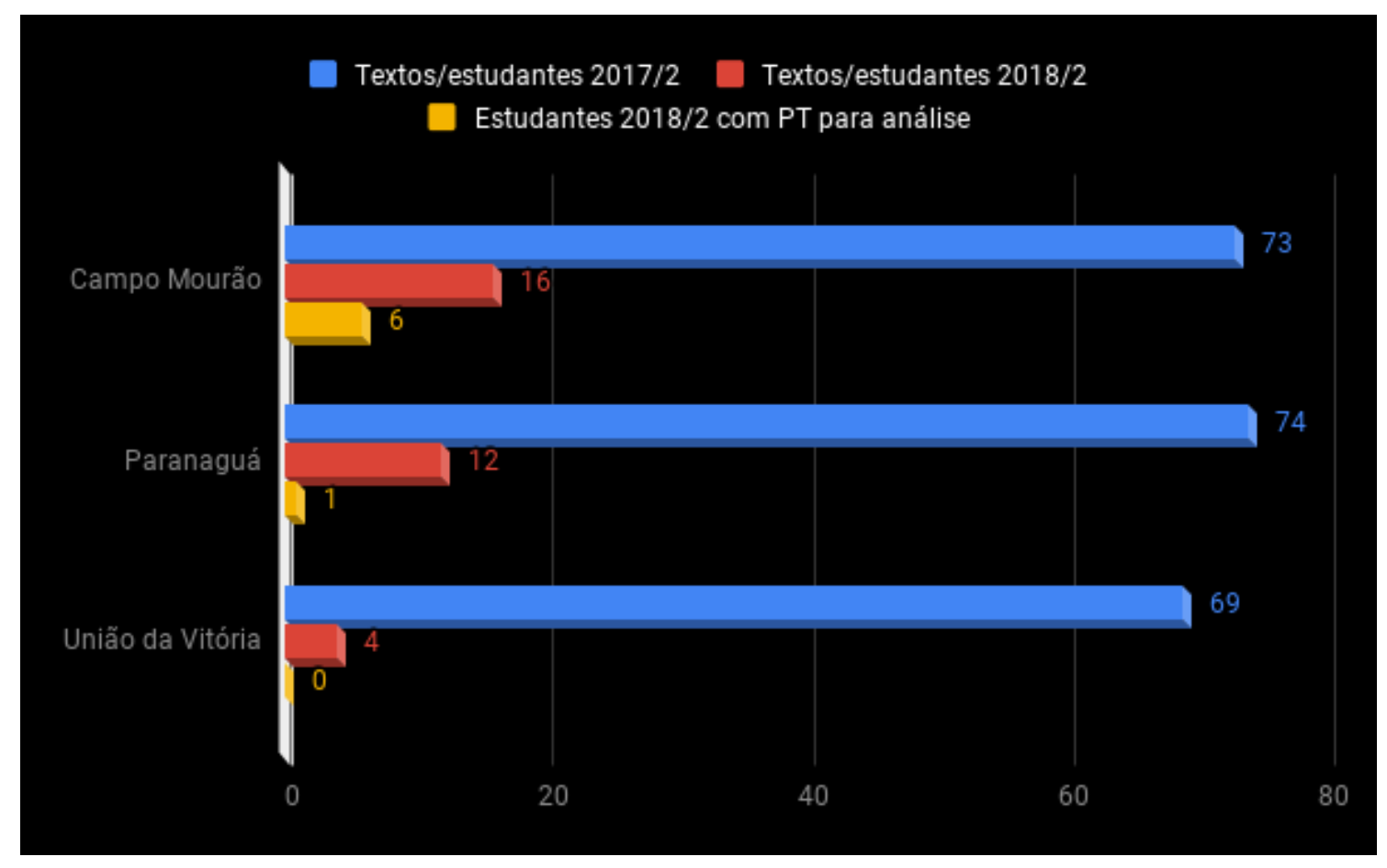

Fonte: os autores.

A cada semestre, o PFI matriculou, por meio de teste seletivo, aproximadamente 20 estudantes para preencher as vagas disponíveis nas 9 turmas distribuídas nos campi, conforme critérios de maior demanda (de nivelamento, de horário etc). Assim, em 2017/2, foram formadas 9 turmas cujo nível de inglês focado era o pré-intermediário, pois essa era a maior demanda apresentada no momento com $47 \%$ dos estudantes nesse nível (SILVA; SILVA, 2018, p. 563).

Como foi realizado teste seletivo no início de cada semestre e como os estudantes aprovados/as puderam continuar no semestre conseguinte, a cada período, formaram-se turmas híbridas com estudantes do semestre anterior bem como estudantes novos/as.

Dessa forma, em 2018/2, apenas 7 estudantes participaram efetivamente dos 3 semestres e realizaram ambas PT. Isso explica o número de PT disponíveis para análise, sendo que cada estudante tem dois textos (uma versão de 2017/2 e uma de 2018/2), conforme terceira coluna do Gráfico 1. Isso nos permitiu analisar o desenvolvimento da escrita em LI desses estudantes, considerando uma versão quando entraram no Programa e uma versão após cerca de 1 (um) ano e meio com as mediações dos professores bolsistas e das atividades de escrita identificadas. 


\section{DISCUSSÃO DOS RESULTADOS}

\section{Contexto de ensino do PFI}

Tendo como objetivo geral investigar o processo de aprendizagem da escrita em língua inglesa referente à potencialidade de desenvolvimento dos PPS a partir de produções textuais de participantes do Programa Paraná Fala Inglês da Unespar, delimitamos nossa exposição via objetivos específicos. O primeiro recai sobre a identificação do contexto em que o processo de aprendizagem se insere a partir do material de planejamento dos professores do programa.

O contexto de ensino que se dá no PFI Unespar se configura internamente com uma equipe interna de 6 bolsistas, sendo uma coordenação institucional e outra pedagógica (docentes da universidade), um bolsista graduando e 3 professores de LI, que atuam cada um em um campus da instituição, a saber, campus de Campo Mourão (CM), Paranaguá (PG) e União da Vitória (UV) ${ }^{11}$, conforme Figura 1:

Figura 1: Organização PFI Unespar.

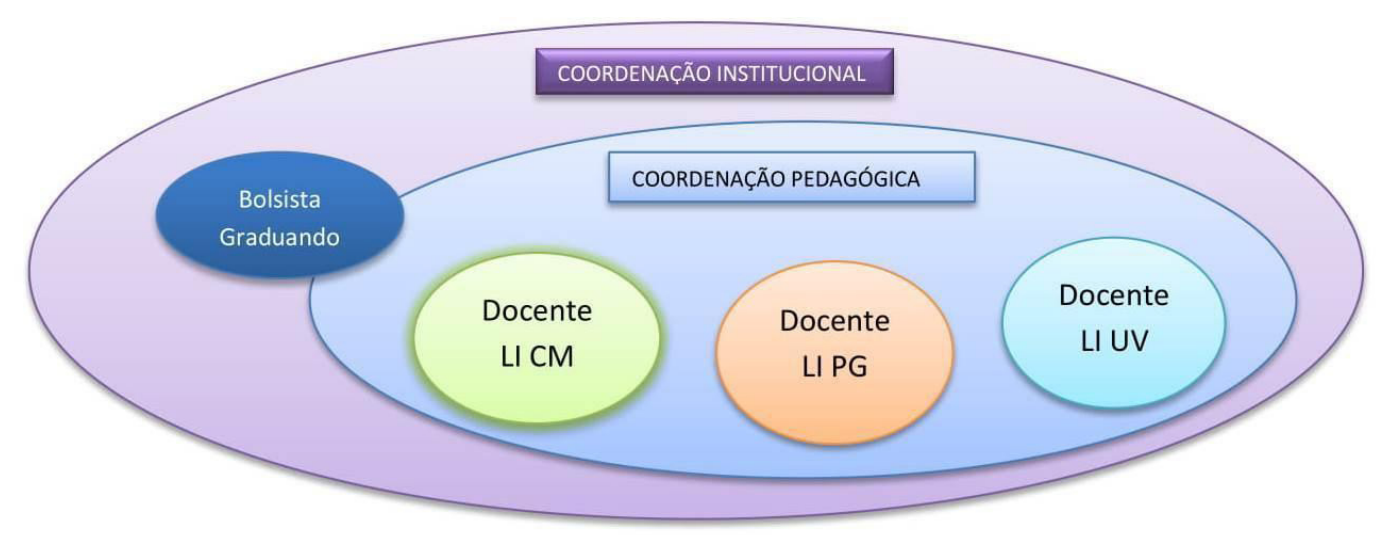

Fonte: Adaptado de Unespar (2019).

Em cada campus os/as professores ministravam aulas para 3 turmas de aproximadamente 20 estudantes do nível pré-intermediário ou superior, também desenvolviam projetos de pesquisa e extensão no âmbito do Programa.

\footnotetext{
${ }^{11}$ Atualmente, o campus de Apucarana ocupa o lugar do Campus de União da Vitória. Além disso, em contexto de pandemia dado pela COVID-19, o Programa passou a atender todos os campi da universidade.
} 
O material didático utilizado adveio da plataforma online SmrtEnglish ${ }^{12}$, produzido pelo Canadian College. Em se tratando de uma política executada em uma universidade multicampi, o trabalho com a internet e suas ferramentas tomava um protagonismo na organização. Para tanto, cada campus é equipado com um laboratório com notebooks e acesso à rede mundial de comunicação. Assim, o Programa funciona também como uma ação de letramento digital às pessoas envolvidas.

Para atender ao primeiro objetivo específico da pesquisa, para além do contexto geral do PFI exposto acima, coletamos os relatórios pedagógicos mensais escrito pelos professores bolsistas do início de cada semestre delimitado para pesquisa, a saber, 2017/2 (agosto a dezembro), 2018/1 (janeiro a julho) e 2018/2 (agosto a dezembro).

Os relatórios mensais, doravante $\mathrm{RM}$, tinham por objetivo materializar linguisticamente o relato do trabalho realizado pelos professores do PFI. Além de registro de atividades já realizadas, também tinham como atribuição registrar o planejamento para aulas posteriores. Este planejamento auto-prescrito ${ }^{13}$ aparece somente no primeiro relatório de cada semestre. Os RM variam em número de laudas de forma que os primeiros continham cerca de 50 páginas e os últimos, 10 páginas. No entanto, nota-se que os últimos estão mais organizados e algumas informações aparecem anexas. Genericamente, são subdivididos em seções, a saber: identificação e tramitação, planejamentos e relatórios, carga horária e assinaturas/pareceres da coordenação.

Ainda em relação ao planejamento, identificamos uma melhora gradativa na organização dos documentos. O planejamento referente ao semestre 2018/2, por exemplo, diferentemente dos anteriores, foi organizado em conjunto em apenas um documento, trazendo uma diretriz comum ao Programa no que tange aos aspectos pedagógicos.

A partir de uma análise quantitativa do total de atividades planejadas, pudemos identificar que $10 \%$ focam em atividades de escrita, assim, houve oportunidade de aprendizagem da modalidade escrita, embora em um número bem reduzido de atividades. Houve, especificamente, atividades de produção de parágrafos, o que proporcionou oportunidades de aprendizagem desse conteúdo aos estudantes do PFI, convergindo com um dos focos de atenção delimitado no comando de PT que analisamos neste trabalho: produção de um parágrafo.

A partir do levantamento quantitativo, ao sistematizarmos as informações, identificamos tanto prescrições de atividades de escrita advinda do material didático

\footnotetext{
${ }^{12}$ Disponível em: http://smrtenglish.com/unespar/. Acesso em: 14 fev. 2019.

${ }^{13}$ Com base em Clot (2007), "o trabalho prescrito diz respeito àquilo que é prescrito ao professor ou àquilo que ele prescreve a si mesmo" (SILVA, 2015, p. 36).
} 
quanto propostas outras, acrescidas pelos professores. Consideramos como atividade de escrita toda produção textual demandada pelo professor ao estudante.

Em síntese, em relação ao contexto de aprendizagem, delimitado nesta pesquisa no contexto de ensino, especificamente sobre o planejamento de atividades escritas, concluímos que houve planejamento de momentos para realização de atividades de escrita, sobretudo acerca da produção de parágrafo e reescrita (proofreading). Houve, também, um direcionamento para uma diretriz comum de planejamento pedagógico que materializou na articulação dos professores e coordenação pedagógica ao pensarem e organizarem as atividades do curso conjuntamente, considerando, porém, as especificidades de cada contexto.

Avançamos para a análise do comando de produção escrita levantando seus Focos de Atenção.

\section{Análise do comando de produção escrita - Focos de Atenção, critérios de produção e articulação com os PPS}

Damos início à análise do comando de produção para respondermos quais FA estão presentes no comando de produção escrita. Para tanto, utilizamos do procedimento de análise de orientação e tratamento temático, no qual fizemos o levantamento do segmento de orientação temática, SOT, ou seja, o tema principal (BRONCKART, 2008). Na sequência, reproduzimos o comando de produção analisado:

Figura 2: Comando de produção.

\section{Writing Assessment}

In the space below, write in proper paragraph format the extent to which you agree or disagree with the statement below. You will be assessed on the organization, grammar and use of examples. (8-15 lines)

\section{Some students travel abroad for one year before starting university. What are the advantages and disadvantages of doing this?}

Fonte: dados coletados do PFI.

A partir da reprodução do comando acima, identificamos que o SOT do comando é PRODUÇÃO ESCRITA DE UM PARÁGRAFO ARGUMENTATIVO SOBRE VIAGENS. Essa identificação foi realizada a partir dos sintagmas nominais 
e verbais predominantes, conforme grifo em negrito nos termos "writing assessment", "write", "agree or disagree", "travel", "advantages and disadvantages". A partir desse levantamento, podemos inferir que os FA estão voltados:

FA1: para a produção escrita de um parágrafo;

FA2: para uma sequência argumentativa; e

FA3: para a temática viagens.

Os FA identificados, como conteúdos da produção, convergem, também, com os critérios que devem ser atendidos pelos estudantes em suas PT expostas explicitamente no comando (Quadro 3). No entanto, mesmo que explícitos, a apreensão deles pelo estudante dependerá do desenvolvimento dos seus PPS. Por exemplo, para atender ao que se pede e escrever um parágrafo, o estudante deverá saber previamente o conceito científico de parágrafo.

Expomos no Quadro 3 a síntese dos critérios que foram elaborados a partir do resultado da análise do comando e, posteriormente, utilizados para análise das PT.

Quadro 3: Síntese dos critérios de análise das PT a partir dos FA.

\begin{tabular}{|c|c|}
\hline FA/Critérios & Desdobramento específico \\
\hline \multirow{5}{*}{$\begin{array}{l}\text { FA1: produção escrita de um parágrafo - produzir um } \\
\text { protótipo de parágrafo de } 8 \text { a } 15 \text { linhas que contenha um } \\
\text { tópico desenvolvido sobre a temática proposta; atender às } \\
\text { regras gramaticais de uso da norma culta/urbana da língua } \\
\text { inglesa, bem como estruturação organizacional do texto. }\end{array}$} & Parágrafo \\
\hline & 8-15 linhas \\
\hline & $\begin{array}{l}\text { Tópico (critério do próprio } \\
\text { material da SmrtEnglish) }\end{array}$ \\
\hline & Gramática/norma \\
\hline & Estrutura textual \\
\hline \multirow{4}{*}{$\begin{array}{l}\text { FA2: sequência argumentativa - responder à pergunta } \\
\text { concordando ou não com a afirmativa; utilizar-se de } \\
\text { operadores argumentativos explicitamente, apresentando } \\
\text { argumentos por meio de exemplos que se adequam à } \\
\text { temática proposta. }\end{array}$} & Resposta \\
\hline & Posicionamento \\
\hline & Operadores argumentativos \\
\hline & Argumentos/exemplos \\
\hline \multirow{2}{*}{$\begin{array}{l}\text { FA3: temática viagens - tratar explicitamente da temática } \\
\text { viagens, especificamente se há ou não vantagens de viajar } \\
\text { antes de iniciar graduação, com apresentação de exemplos } \\
\text { coerentes ao tema. }\end{array}$} & Temática (amplo) \\
\hline & Tema (específico) \\
\hline
\end{tabular}

Fonte: os autores. 
A partir do levantamento temático na identificação dos FA apresentados no comando e a partir da sumarização da literatura acerca de alguns PPS, especialmente aqueles que são predominantes na atividade adulta, conforme Silva (2015), desenvolvemos algumas articulações entre os FA e os PPS a fim de identificar possíveis potencializadores de desenvolvimento na escrita dos textos analisados (ver Figura 3).

Os critérios de produção aparecem no comando de forma implícita. Eles servem tanto para direcionar a produção escrita do estudante quanto para posterior avaliação a ser realizada pelo professor. Assim, a análise dos Focos de Atenção depreende e sumariza, neste caso, os conteúdos cuja atenção do/a estudante é direcionada. Por exemplo, delimitamos um foco de atenção que se volta para uma sequência argumentativa. Consoante ao FA, um dos critérios de produção analisados é a aparição de argumentatividade (por meio de operadores argumentativos e exemplificação).

Isso ficou explícito a partir de dois trechos do comando que exigem tomada de posicionamento, conforme marcado em negrito:

i. [...] write in proper paragraph format the extent to which you agree or disagree with the statement below;

ii. What are the advantages and disadvantages of doing this?

Assim, partimos para a terceira etapa da pesquisa que ensejou responder quais PPS puderam ser potencializadas para desenvolvimento no curso do PFI a partir da análise das produções escritas.

\section{Potenciais de desenvolvimento dos PPS no processo de escrita}

$O$ que os FA identificados podem implicar em termos de processos potencializadores de desenvolvimento? Quais PPS podem ser potencializados com o comando de produção a partir da análise temática? Essas são questões norteadoras para discutir nossa terceira etapa da pesquisa.

$\mathrm{Na}$ periodização do desenvolvimento humano, os PPS tomam protagonismo em determinados períodos de desenvolvimento do sujeito. Por exemplo, na primeira infância, a atividade principal de desenvolvimento da criança é a emocional, na qual atividades para desenvolver seu psiquismo devem abranger contato físico direto (sensação e percepção). Na atividade de estudo, considerando a entrada da criança no processo formal de aprendizagem - a escola - procura-se desenvolver a linguagem, por exemplo, com o ensino da escrita. 
Para adultos, consideramos que atividades que busquem desenvolver a generalização e abstração sejam mais adequadas, pois para que um estudante tenha possibilidade de desenvolver ambos processos psíquicos, PPI E PPS mais basilares, como a sensibilidade, percepção, linguagem, dentre outras, já devem estar em um estágio mais avançado de desenvolvimento.

Com critérios do Quadro 3, analisamos linguisticamente as PT e inferimos conceitos de 0 a 10, no qual 0 não atendia ao critério solicitado e 10 o atendia integralmente. Assim, na linha vertical do Gráfico 2, a seguir, temos a média final de cada PT. Abaixo, expomos a síntese dos resultados de análise das duas versões das produções textuais dos 7 estudantes participantes desta pesquisa.

Gráfico 2: Potenciais de desenvolvimento entre a $1^{\mathrm{a}}$ e $2^{\mathrm{a}}$ versão da PT.

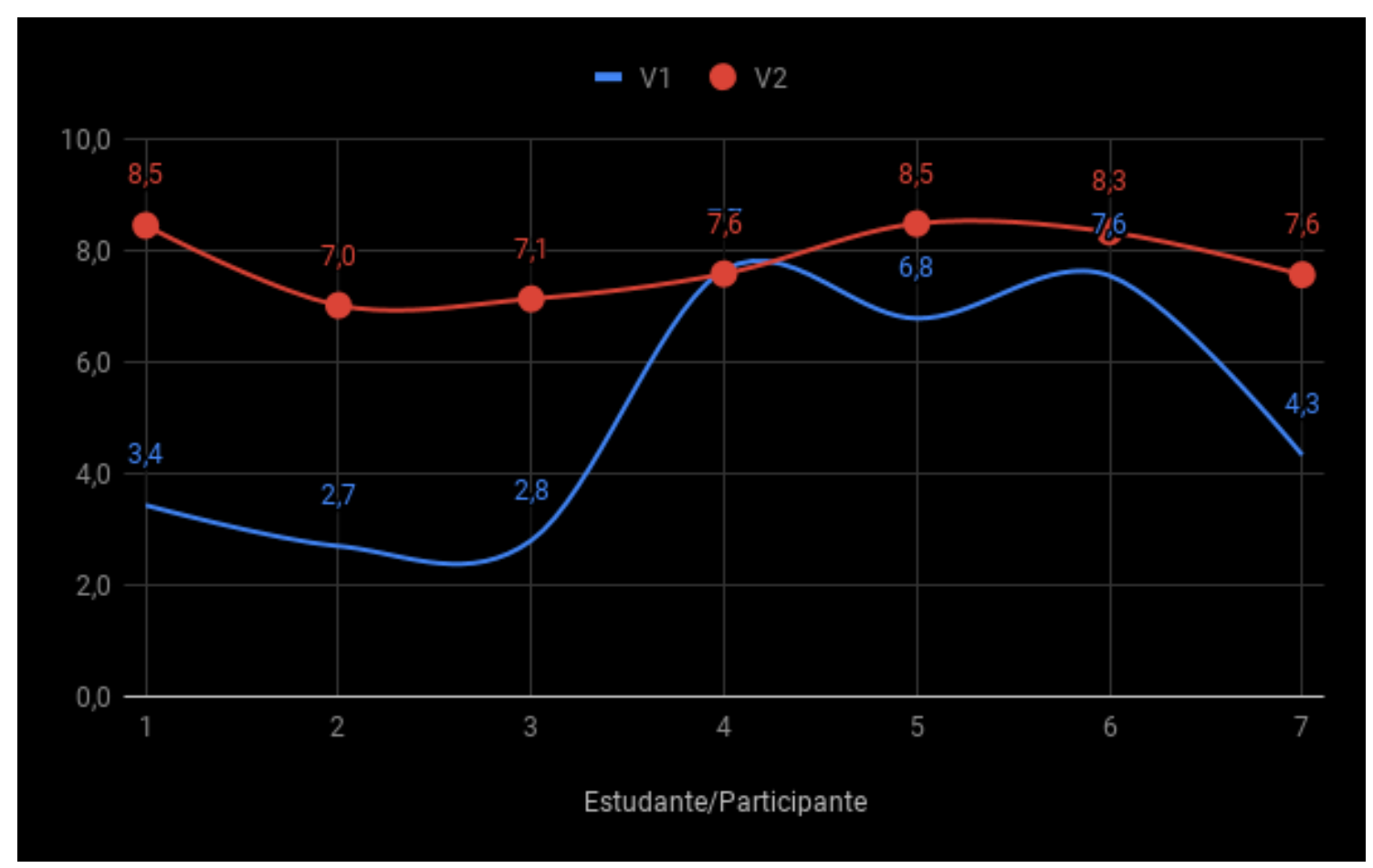

Fonte: os autores.

A partir da análise, pudemos perceber que, além da articulação dos PPS, há uma diversidade de nivelamentos, em se tratando especificamente da capacidade de escrita em LI.

Também identificamos casos em que estudantes deixaram de atender critérios na segunda versão que atenderam na primeira (estudantes 4 e 5). Isso implica na atenção 
voluntária no que se refere a um dos FA delimitados no comando de produção produção de um parágrafo.

A primeira versão da PT estava situada em um contexto de seleção de estudantes para o curso e a segunda versão em um contexto de avaliação. Isso pode ter implicado no desvio do foco de atenção, levando os/as estudantes a, talvez, pensarem "que se escrever mais, minha produção será melhor avaliada" na segunda situação de aplicação. Assim, desviando a atenção para do número de linhas delimitadas no comando (ambas as PT excedem o número de linhas delimitadas). Por outro lado, a maioria das produções ascendem no que diz respeito ao FA2.

As produções mostram mais explicitamente o posicionamento de seus sujeitosprodutores, bem como há a utilização dos operadores argumentativos. Isso demonstra um potencial de desenvolvimento de abstração e generalização das formas linguísticas para seus usos reais por meio de sua apropriação conscientizada.

Por fim, expomos a Figura 3, que sintetiza resultados da pesquisa ao mostrar as articulações entre os FA/critérios de produção escrita e os PPS potencialmente desenvolvidos.

Figura 3: Articulação entre os FA/critérios produção escrita e os PPS.

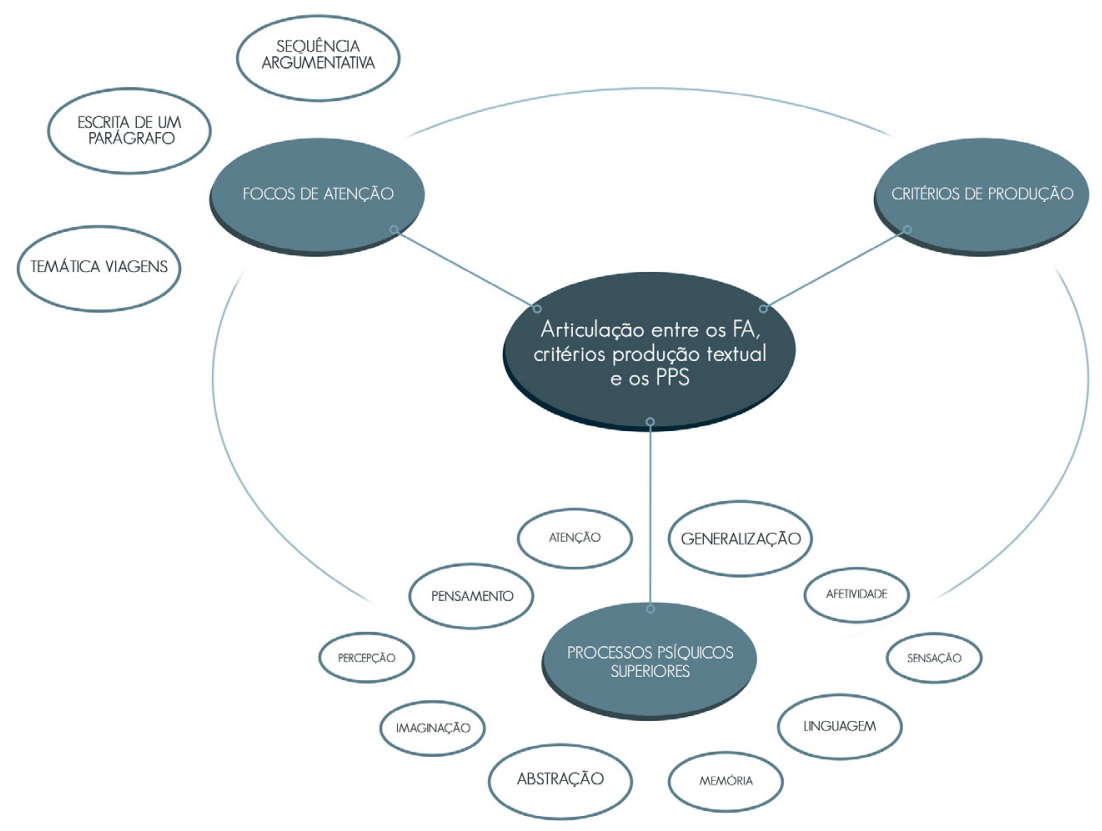

Fonte: os autores. 
Como podemos observar, a articulação entre essas questões, tendo como complementação, também, o contexto/situação de produção (conforme exposto), são indissociáveis e complementares. O que nos aponta para uma tomada de consciência não só para a produção do material didático (que foge, às vezes, da atribuição do/a docente), mas à escolha e organização do ensino para que proporcione ao sujeito aprendiz oportunidades de desenvolvimento dos PPS. Nessa pesquisa, identificamos essas oportunidades em momentos os quais as produções textuais dos estudantes demonstraram capacidade argumentativa e exposição de posicionamento na segunda versão da PT, potencializando, sobretudo, o desenvolvimento da abstração e generalização, conforme destacado pela Figura 3.

Por fim, os PPS foram expostos na figura de acordo com o potencial de desenvolvimento de cada um. Acreditamos que, mesmo em se tratando de processos articulados, quando tratamos de ensino de língua estrangeira para adultos, alçamos desenvolver nos estudantes PPS mais avançados - como a abstração e a generalização — considerando a periodização (MARTINS, 2013).

\section{CONSIDERAÇÕES FINAIS}

Dialogar com diferentes áreas do conhecimento é um desafio que colocamos em pauta neste trabalho, incluindo a Linguística Aplicada, a Psicologia e a Educação. No entanto, acreditamos que, apesar de diferentes áreas, elas se voltam para a questão do ser humano e sua ação social como ponto convergente.

Dessa forma, congregamos nesta pesquisa o ISD e a PHC para analisar o PFI na sua questão central: a capacitação linguística. Assim, buscamos investigar o processo de aprendizagem da escrita em LI e potenciais de desenvolvimento dos PPS a partir da delimitação de produções textuais de estudantes do PFI Unespar. Os estudantes do Programa e também da pesquisa eram membros da comunidade acadêmica, podendo ser estudantes de graduação e pós-graduação, agentes universitários ou docentes.

O objetivo geral desmembrou-se em objetivos específicos transformados nas seguintes perguntas de pesquisa: a) qual o contexto de aprendizagem (delimitação no ensino) em que os estudantes se inserem a partir do material de planejamento dos professores? b) Quais Focos de Atenção estão presentes no comando de produção escrita? c) Que potenciais de desenvolvimento há na atividade de escrita delimitada em termos de desenvolvimento dos PPS?

A partir dos resultados da investigação, temos as seguintes considerações/ respostas para as perguntas específicas: a) identificação de possibilidades de Revista X, v. 16, n. 3, p. 822-846, 2021. 
aprendizagem da escrita em língua inglesa contemplados no planejamento curricular; b) melhoras gradativas na organização pedagógica do planejamento; c) oportunidade de letramento digital aos estudantes; d) levantamento dos Focos de Atenção que estão voltados para a produção escrita em uma sequência argumentativa e temática viagens; e) identificação de potenciais de desenvolvimento dos PPS nas produções textuais de forma articulada entre si; e f) expansão da capacidade da argumentatividade e exposição de posicionamento articulado com potencial desenvolvimento da abstração e generalização de conceitos articulados, sobretudo a atenção.

Esta pesquisa nos proporcionou analisar em que aspectos o PFI tem contribuído para a formação linguístico-discursiva de seus estudantes em termos de potenciais de desenvolvimento dos PPS em adultos. Assim, buscamos articular a discussão acerca da emergência das políticas de capacitação linguística (inseridas no roll de políticas de internacionalização) articuladas com o processo de aprendizagem de línguas, em especial, seu impacto no desenvolvimento psíquico dos estudantes participantes.

\section{AGRADECIMENTOS}

Agradecimentos à Unespar, mais especificamente ao PFI Unespar, ao Grupo de Pesquisa Lidere/CNPq, ao Colegiado de Letras e ao Programa de Iniciação Científica. Agradecemos também à SETI e à UGF-PR.

\section{REFERÊNCIAS BIBLIOGRÁFICAS}

BRONCKART, J. P. Atividade de linguagem, textos e discursos: Por um interacionismo sociodiscursivo. Tradução de: MACHADO, A. R.; CUNHA, P. 2. ed. São Paulo: EDUC, 2007.

BRONCKART, J. P. O agir nos discursos: das concepções teóricas às concepções dos trabalhadores. Tradução de: MACHADO, A. R.; MATENCIO, M. L. M. Campinas: Mercado de letras, 2008.

CLOT, Y. A função psicológica do trabalho. Tradução de: SOBRAL, A. 2.ed. Petrópolis, Revista: Vozes, 2007.

CRISTOVÃO, V. L. L. Interacionismo Sociodiscursivo (ISD): quadro teóricometodológico para estudos da linguagem. In: CRISTOVÃO, V. L. L. (org.). Estudos da linguagem à luz do interacionismo sociodiscursivo. Londrina: UEL, 2008, p. 3-12. 
CRISTOVÃO, V. L. L.; MOTT-FERNANDEZ, C. Identificação do movimento de organização temática no discurso oral. In: GONÇALVES, A. V.; SILVA, W. R.; GÓIS, M. L. S. (orgs.). Visibilizar a Linguística Aplicada: abordagens teóricas e metodológicas. Campinas: Pontes Editores, 2014, p. 131-153.

EL KADRI, A.; DI RAIMO, V. Globalization and the teaching of foreign languages: The case of Paraná Speaks English Program. In: GIMENEZ, T. et al (orgs.). Language Issues in a Global World: Insights from Brazil. Londrina: Edição do autor, 2017, p. 64-73.

EL KADRI, M. S.; GIMENEZ, T.; EL KADRI, A. Representações sobre o programa "Paraná Fala Idiomas - Inglês" sob as lentes do Ciclo de Política e da Análise do Discurso Crítica. Entrepalavras, Fortaleza, v. 9, n. 3, p. 421-441, set./dez. 2019.

LANFERDINI, P. A. F. O trabalho (agir) docente no processo coletivo de planejamento e elaboração de uma sequência didática para o ensino deLíngua Inglesa. 2012. Dissertação (Mestrado em Estudos da Linguagem) — Universidade Estadual de Londrina, Londrina, 2012.

LÜDKE, M.; ANDRÉ, M. E. D. A. Pesquisa em educação: abordagens qualitativas. São Paulo: EPU, 1986.

MACHADO, A. R.; BRONCKART, J. P. (Re)configurações do trabalho do professor construídas nos e pelos textos: a perspectiva metodológica do Grupo ALTER-LAEL. In: ABREU-TARDELLI, L. S.; CRISTOVÃO, V. L. L. (orgs.). O Trabalho do Professor em uma Nova Perspectiva. Campinas: Mercado de Letras, 2009. p. 31-77.

MARSON, I. C. V.; BORGES, E. F. V. "Paraná Fala Inglês" na UEPG: experiência extensionista com foco na mobilização internacional. Revista Eletrônica de Extensão. Florianopolis, v. 12, n. 20, p. 73-89, 2015.

MARSON, M. Z.; FURTOSO, V. B. O projeto Paraná Fala Inglês no contexto sóciohistórico de internacionalização das universidades brasileiras. In: CONELIN CONGRESSO DE ESTUDOS DA LINGUAGEM, 3., 2015, Cornélio Procópio. Anais [...]. Cornélio Procópio: UENP, 2015. p. 700-715. Disponível em: http://media.wix.com/ ugd/380404_0c21b43c6b0c4d40bdb8ef5bcae6a7b6.pdf. Acesso em: 25 ago. 2020.

MARSON, M. Z. Ensino de inglês e a internacionalização do ensino superior: percepções sobre o Programa "Paraná Fala Inglês" na UEL. 2017. Dissertação (Mestrado em Estudos da Linguagem) — Universidade Estadual de Londrina, Londrina, 2017.

MARTINS, L. M. O Desenvolvimento do Psiquismo e a Educação Escolar: contribuições à luz da psicologia histórico-cultural e da pedagogia histórico-crítica. Campinas, São Paulo: Autores Associados, 2013. 
MARTINS, L. M. O Desenvolvimento do Psiquismo e a Educação Escolar: contribuições à luz da psicologia histórico cultural e da pedagogia histórico-crítica. 2012. 250 f. Tese (Livre-Docência) — Curso de Psicologia da Educação, Departamento de Psicologia, Universidade Estadual Paulista Júlio de Mesquita Filho, Bauru, 2012. Disponível em: https://formacaodocente.files.wordpress.com/2012/09/martins_ligia__o_desenvolvimento_do_psiquismo_e_a_educacao_escolar.pdf. Acesso em: 02 maio 2021 .

PETRECHE, C. R. C.; SENEFONTE, F. H. R. The Internationalization of UENP: Realities and future prospects. In.: GIMENEZ, T. et al (Orgs.). Language Issues in a Global World: Insights from Brazil. Londrina: Edição do autor, 2017, p. 13-30.

PINHEIRO, N. G.; BARETTA, L.; SOUZA, C. A. R. Programa O Paraná Fala Inglês (PFI): breve histórico do projeto na Unicentro. In: SEMANA DE INTEGRAÇÃO: ENSINO, PESQUISA E EXTENSÃO: DIREITOS HUMANOS: DIALOGANDO SOBRE A DIVERSIDADE, 5., 2017, Guarapuava. Anais da V SIEPE. Guarapuava: Unicentro, 2017. Disponível em: https:/evento.unicentro.br/files/Submissaoxarquivos/ car_submissao/31_08_2017_car_submissao_1406544488.pdf. Acesso em: 13 ago. 2020.

QUADROS-ZAMBONI, A. S. O processo de internacionalização no ensino superior brasileiro: um estudo de caso sobre a Universidade Estadual do Paraná. 2018. Tese (Doutorado em Letras) — Universidade Federal do Paraná, Curitiba, 2018.

RODRIGUES, J. T.; BECHER, T. C.; BUSSE, S. A intrínseca relação entre o ensino de Língua Inglesa e o senso de identidade do aprendiz: um estudo aplicado. Web Revista SOCIODIALETO, v. 9, n. 25, p. 45-68, abr. 2019. Disponível em: http://sociodialeto. com.br/index.php/sociodialeto/article/view/126. Acesso em: 13 ago. 2020.

SANCHES, G. J. O Programa Paraná fala Inglês: uma autoetnografia sobre concepção de língua e uso de material didático em sala de aula. 2019. Dissertação (Mestrado em Letras) - Universidade Federal do Paraná, Curitiba, 2019.

SENEFONTE, F. H. R. Research on the Paraná Speaks English program: a bibliographic analysis. Claraboia, Jacarezinho/PR, v. 12, p. 89-98, jul./dez, 2019.

SANTOS, S. S.; TULIO, M. O Paraná fala Línguas Estrangeiras segunda etapa O Paraná fala Inglês. In: ENCONTRO CONVERSANDO SOBRE EXTENSÃO NA UEPG - CONEX, 16., 2018, Ponta Grossa. Anais do $16^{\circ}$ CONEX. Ponta Grossa: UEPG, 2018. Disponível em: https://sites.uepg.br/conex/anais/anais_2018/ arquivos/04152018_100411_5ad354d3a5ecf.pdf. Acesso em: 13 ago. 2020. 
SILVA, A. A. P. O trabalho do professor formador de lingua inglesa e a natureza de aprendizagem na formação em pré-serviço. 2015. Tese (Doutorado em Estudos da Linguagem) — Universidade Estadual de Londrina, Londrina, 2015.

SILVA, A. D. S; SILVA, A. A. O Programa Paraná fala Línguas Estrangeiras: Reflexões sobre o "Paraná fala Inglês" na Unespar. In: RIOS-REGISTRO, E. S.; NOVELLI, J.; CALVO, L. C. S. (orgs.). Paraná Fala Idiomas — Inglês como política linguística no Paraná: pesquisas, práticas e desafios”. Campinas: Editora Pontes, 2021.

SILVA, A. D. S; SILVA, A. A. P. Políticas de internacionalização: o Programa Paraná fala Inglês na Universidade Estadual do Paraná. In: COLÓQUIO INTERNACIONAL DE ESTUDOS LINGUÍSTICOS E LITERÁRIOS, 5., 2018, Maringá. Anais [...]. Maringá: UEM, 2018, p. 554-566.

SILVA, A. D. S; SILVA, A. A. P. Processo de aprendizagem e desenvolvimento da Língua inglesa no contexto do Programa Paraná Fala Inglês. In: CONGRESSO INTERNACIONAL DE ESTUDOS DA LINGUAGEM - CIEL, 3., 2019, Ponta Grossa. Anais eletrônicos... Ponta Grossa: UEPG, 2019, p. 1658-1669. Disponível em: https:// ppgeluepg.wixsite.com/ciel/publicacoes. Acesso em: 25 jan. 2020.

UNESPAR. RESOLUÇÃO $N^{o}$ 015/2020 - REITORIA/UNESPAR. Cria o Programa Unespar Fala Espanhol (UFE) e dá outras providências. Paranavaí: Reitoria Unespar, 2020. Disponível em: https://www.unespar.edu.br/projetos/ufe/ resolucao015_2020criaparanafalaespanhol.pdf. Acesso em: 21 abr. 2021.

UNESPAR. Paraná Fala Inglês Unespar. Unespar. 18 de maio 2017. Disponível em: http://www.unespar.edu.br/paranafalaingles/equipe. Acesso em: 14 fev. 2019.

VIGOTSKI, L. S. A construção do pensamento e da linguagem. Tradução de: BEZERRA, P. 2. ed. São Paulo: Editora Martins Fontes, 2009. 